\title{
Correspondence
}

\section{Depressive disorder in adolescents}

Sir: Professor Harrington (1996) commences his article on a note of assurance, which is that, in the past decade, there has been progress toward "greater diagnostic refinement" in depressive disorders in this age group. He also ends on this up-beat note and concludes that better diagnosis will lead, not only to improved application of treatment methods, but also to greater knowledge concerning prevention and recurrence of depressive disorder. Unfortunately, he has given no indication in the intervening paragraphs to show that such advance has occurred, although there is again emphasis on the need for "accurate diagnosis". He appears to downgrade such standard systems as the DSM definitions but indicates that severity is best determined by establishment of duration of the disorder. If, he states, depression is a prominent part of the clinical picture, the likelihood of the presence of a depressive disorder is greater and that in such cases, the disorder is more likely to persist.

Harrington considers that a principle of treatment is reassurance and that the adolescent patient should be assured that the disorder will probably resolve "in a few months", but he seems to overlook the fact that one reason the general practitioner may have for referral to a psychiatrist is the chronicity of the disorder. Does Professor Harrington provide the same assurance to a patient whose disorder has lasted a year, or is clearly an aspect of personality disorder, as to the patient who has an acute episode arising in the setting of normal personality, absence of severe stress and good personal relationships? He does not like the distinction between "endogenous" and "reactive"; certainly these have become outmoded terms and there is seldom a clear distinction but surely the assessment of the supposed degree to which adversity plays a role in the genesis of the disorder is some guide to treatment.

It is evident that he does not place much faith in the therapeutic potential of pharmacotherapy and other somatic treatments, and quotes the findings from a study of his own which indicated that tricyclic antidepressants did not "show significant benefits". My examination of that paper revealed that very few studies in the adolescent age range had been conducted but that improvement figures varied between 33 and $45 \%$. Moreover, more recent studies, in which a combination of lithium and a tricyclic had been used, were very suggestive of a beneficial effect. Incidentally, Harrington also considered the role of tricyclic antidepressants in the treatment of major depression in prepubescent patients and again he dismisses their possible value; he quotes the study of Puig-Antich et al (1987) as being the best study available at the time and implied that the drug had no real role since the outcome (of the placebo-controlled study) was "not significant". In fact, those authors had concluded that there was a very apparent effect, that this was dose-related and that studies using higher doses should be conducted. Harrington omits reference to the recent meta-analysis of the effect of antidepressants in young people (Hazell et al, 1995) even though this would seem to provide support for his view; however, those concerned with this matter should also read the subsequent correspondence (Anderson, 1995). Despite his statement that there is little ground to recommend prescription of tricyclics in depressed adolescents, he nevertheless concludes that they should be prescribed on a 'take-it-and-see' basis if "typical disorders" are present; unfortunately he does not indicate how such a typical state of depression may be recognised. Apparently he reserves the use of the drugs for those patients who have failed to respond to psychological treatment; but is this not putting the use of the treatments the wrong way round considering that depressive disorders, or at least those which arrive for psychiatric advice, cause great suffering, loss of educational opportunities and strain on personal relationships? Surely, since there is doubt about the outcome with both pharmacological and psychological approaches, then the quicker road to recovery should be tried first.

What, of course, is required is much better knowledge of the clinical indications for the choice 
of one or the other treatment but Harrington's article leaves one no wiser. It is all very well to blandly recommend psychological treatments but these are costly in terms of skilled therapists and time; such resources may well be available in academic departments but, in the wider world, they are not available and it is wrong to assume otherwise.

Confusion surrounding the term 'depression' persists and will probably continue as long as it continues to be used. Its introduction into psychiatric parlance, in the expectation that everyone should understand "exactly what was meant" (Meyer, 1905) has not been the case; indeed the reverse has occurred. I support the growing realisation (Costello, 1982; van Praag, 1992) that advance will not come by way of study of the overinclusive syndromes but by much closer attention to individual psychopathological features, even single symptoms. Farmer \& McGuffin (1989) called for a "new approach" to the classification of depressive disorders. They did not indicate what this should be but I have suggested one possibly fruitful line (Snaith, 1995). I see no reason for this not to apply in the field of adolescent as well as adult mood disorders.

Academic psychiatry will have failed in its important task if it does not provide working clinicians and general practitioners with much clearer information than is at present available.

Anderson, I. (1995) Place of tricyclics in depression of young people is not proved (letter). British Medical Journal, 311, 390.

Costello, C. G. (1992) Research on symptoms versus research on syndromes. Arguments in favour of allocating more research time to the study of symptoms. British Journal of Psychiatry, 160, 304-308.

Farmer, A. \& McGuffin, P. (1989) The classification of the depressions. Contemporary confusion revisited. British Journal of Psychiatry, 155, 437-443.

Harrington, R. (1996) Management of depressive disorder in adolescents. Advances in Psychiatric Treatment, 2, 271-277.

Hazell, P., O'Connell, D., Heathcote, D., et al (1995) Efficacy of tricyclic drugs in treating child and adolescent depression. British Medical Journal, 310, 897-900.

Meyer, A. (1905) (Discussant in) The classification of melancholia. Journal of Nervous and Mental Disorders, 32, 112-117.

Snaith, R. P. (1995) Depression: a need for new directions in practice and research. Journal of Psychosomatic Research, 19, 943-947.

van Praag, H. M. (1992) Reconquest of the subjective. Against the waning of psychiatric diagnosis. British Journal of Psychiatry, 160, 266-271.

Philip Snaith St James's University Hospital, Leeds LS9 7TF

Author's reply: Dr Snaith raises some interesting points about the management of depressive disorder in adolescents. However, most of his ex cathedra statements are not supported by the evidence and could mislead readers of this journal.

I am particularly concerned that he places so much faith in the value of tricyclic antidepressants. Before encouraging the use of these potentially toxic drugs as first-line treatments he really should have read the literature more carefully. Had he done so, he would have found at least four published, randomised, double-blind, placebocontrolled studies of tricyclic antidepressants for adolescents with depressive disorder (Kramer \& Feguine, 1981; Geller et al, 1990; Kutcher et al, 1994; Kye et al, 1996). None has shown clear benefits of active medication over placebo.

Snaith would also have discovered a report about the risk of suicide in depressed young people (Rao et al, 1993). This report is especially relevant because a subgroup of the sample from Rao's study took part in the controlled trial (Puig-Antich et al, 1987) that Snaith wrongly claims showed a "very apparent effect" of tricyclics. Three of the seven suicides found by Rao et al were from tricyclic overdose - 'first do no harm', Dr Snaith.

The other points raised by Dr Snaith can be dealt with quite briefly. He claims that psychological treatments may "well be available in academic departments but, in the wider world, they are not available and it is wrong to assume otherwise". Once again, $\mathrm{Dr}$ Snaith has not done his homework. A few telephone calls to non-academic child and adolescent mental health services would have quickly shown that the kinds of psychological treatments that I described in my article, such as cognitive-behavioural therapy and family therapy, are widely available within the NHS.

Dr Snaith states that "better knowledge of the clinical indications for the choice of one or the other treatment" is required, and I agree. However, there have been no systematic published trials comparing pharmacological and psychological approaches to depressive disorder in adolescents. Until the results of such trials become available, we will have to proceed on the basis of the evidence that has been published up to now. Studies of medication have consistently shown that it is no better than placebo. By contrast, studies of psychological treatments for clinically diagnosed adolescents with depressive disorder have generally shown significant benefits over comparison conditions (Lewinsohn et al, 1990; Hops \& Lewinsohn, 1995; Wood et al, 1996) and psychological treatments may have a preventive effect (Clarke et al, 1995). Therefore, the available data suggest that in most cases of adolescent depressive disorder the firstline treatments should be psychological not pharmacological. 